\title{
Expiratory flow limitation during sleep in heavy snorers
}

\author{
D. Stănescu, S. Kostianev, A. Sanna, G. Liistro, Cl. Veriter
}

\begin{abstract}
Expiratory flow limitation during sleep in heavy snorers and obstructive sleep apnoea patients. D. Stănescu, S. Kostianev, A. Sanna, G. Liistro, Cl. Veriter. C ERS Journals Ltd 1996.

ABSTRACT: Inspiratory flow limitation (FL) during sleep has previously been reported both in obstructive sleep apnoea (OSA) patients and heavy snorers (HS). Recent results from this laboratory have shown the occurrence both of inspiratory and expiratory flow limitation during muscular relaxation in awake healthy subjects and OSA patients.

In this study, we have investigated whether expiratory flow limitation occurs during sleep in heavy snorers and in patients with OSA. We studied four nonapnoeic, heavy snorers and five OSA patients. Airflow was measured with a pneumotachograph attached to a tight-fitting mask, and supraglottic pressure with a catheter placed at the supraglottic level. Scoring for flow limitation was achieved by visual inspection of $\mathbf{2 0 0}$ breaths recorded during sleep.

About $20 \%$ of the respiratory cycles presented isolated inspiratory flow limitation. Approximately the same percentage was observed in heavy snorers and OSA patients. Isolated expiratory flow limitation was less frequently recorded. Coupled inspiratory and expiratory flow limitations were more numerous, especially in heavy snorers.

We conclude that both in heavy snorers and obstructive sleep apnoea patients, inspiratory flow limitation is associated with expiratory flow limitation. This suggests that upper airway obstruction during sleep is both an inspiratory and expiratory event.

Eur Respir J., 1996, 9, 2116-2121.
\end{abstract}

Pulmonary Laboratory and Division, Cliniques Universitaires Saint-Luc, Brussels, Belgium.

\section{Correspondence: D. Stănescu}

Cliniques Universitaires Saint-Luc Bruxelles

Belgium

Keywords: Flow limitation

sleep

sleep apnoea

snoring

upper airways

Received: October 191995

Accepted after revision April 291996
It is generally accepted that the mechanism responsible for the development of obstructive sleep apnoea (OSA) is the result of an imbalance between negative inspiratory intraluminal pressure and activation of upper airway dilator muscles. This causes narrowing of the upper airway and flow limitation. The latter is characterized by a constant, or even decreased, inspiratory flow, occurring simultaneously with an increased, i.e. more negative, intraluminal pressure. Sleep-related inspiratory flow limitation was reported in healthy, nonobese, nonsnoring subjects [1], healthy snorers [2, 3], and OSA patients $[3,4]$. In the latter, upper airway narrowing may progress to airway occlusion, so that inspiratory flow limitation is followed by apnoea.

Narrowing of the upper airway and flow limitation is not supposed to occur during expiration, since intraluminal, and therefore transmural, pressure is positive, distending the airways. However, recent findings from this laboratory $[5,6]$, as well as previous reports of other authors [7-10], suggest that narrowing of the upper airway and flow limitation is not solely an inspiratory phenomenon. We have recently observed inspiratory and expiratory flow limitation during muscular relaxation in healthy subjects and OSA patients. No flow limitation was recorded when subjects breathed actively, in phase with the respirator $[6,11]$. Recently, KAYALEH $e t$ al. [7] have reported changes in the tidal breath expiratory flow-volume curve in relaxed supine subjects. This was more frequently observed in patients with sleep apnoea and a history of snoring. The authors suggested that these changes reflected expiratory upper airway narrowing. However suggestive these results might be, they are no substitute for actual demonstration of expiratory flow limitation during sleep. Such a demonstration, in heavy snorers and OSA patients, was the aim of this study.

\section{Materials and methods}

We studied four nonapnoeic, heavy snorers (HS) and five OSA patients. Heavy snorers were recruited by means of newspaper advertisement. They had suffered from loud snoring for several years, without other symptoms of OSA. Heavy snorers were admitted to the hospital for a single night, during which measurement of upper airway mechanics was followed by polysomnographic recordings. The OSA patients were admitted to the hospital for two nights. On the first night, polysomnographic recordings were obtained. Measurement 
of upper airway mechanics was performed during the second night. During this night, sleep was assessed using behavioural criteria: absence of response to the environment; apparent state of sleep; and occurrence of snoring. Repeated entrance to the patient's room was the stimulus to test the response to the environment, every 10-15 min. Written, informed consent was obtained from all subjects, and the experiment was approved by the Ethics Committee of our hospital.

Two separate samples of 100 consecutive breaths, selected at random, were analysed for inspiratory and expiratory flow limitation. Flow limitation was defined as an increase in supraglottic pressure occurring simultaneously with a constant or decreased flow rate. The records were scored by two observers together, who were blind to the clinical characteristics of the subjects. The figures reported are the result of their consensus.

Airflow $\left(V^{\prime}\right)$ was measured with a Fleisch No. 2 pneumotachograph, attached to a tight-fitting silicone face mask. Pressure drop across the pneumotachograph was measured by a $\pm 5 \mathrm{cmH}_{2} \mathrm{O}$ Validyne pressure transducer. A silicone paste was inserted between the mask and the subject's face. The mask was found to be free of leaks when breathing a $79 \% \mathrm{He} / 21 \% \mathrm{O}_{2}$ mixture (using a Godart catapherometer), as no helium was detected around the border of the mask. Supraglottic pressure $(P \mathrm{sg})$ was recorded with a $60 \mathrm{~cm}$ long polyethylene catheter (internal diameter (ID) $2 \mathrm{~mm}$ ), placed through one nostril at the supraglottic level, $17 \mathrm{~cm}$ from the nares, under local anaesthesia (10\% lidocaine) and secured in place. The distal end of the catheter was perforated by six holes spread over the $2 \mathrm{~cm}$ section behind the tip, which was sealed. A bias flow $\left(<0.1 \mathrm{~L} \cdot \mathrm{min}^{-1}\right)$ kept the tube free of secretions. A similar catheter was placed into the mask at $3 \mathrm{~cm}$ from the nares. The proximal ends of both catheters were connected to the two sides of a differential pressure transducer (Validyne $\pm 140 \mathrm{cmH}_{2} \mathrm{O}$ ). The lengths of the tubing of the pharyngeal and mask catheters were adjusted to bring the signals into phase. The phase angle between flow and pressure signals was less than $5^{\circ}$ up to $90 \mathrm{~Hz}$. Signals of $V^{\prime}$ and $P_{\mathrm{sg}}$ were simultaneously recorded on tape (Teac R 81 cassette data recorder) for further examination. From the tape, signals of $V^{\prime}$ and $P_{\text {sg }}$ were displayed on a storage oscilloscope and breaths were analysed for flow limitation. Representative examples of inspiratory and expiratory flow limitation were displayed on a recorder versus time. Supraglottic resistance $(R \mathrm{sg})$ was measured on the linear portion of the pressure-flow relationship and is the average of 15 consecutive breaths.
Polysomnographic recordings and sleep staging were assessed using standard procedures [12]. Hypopnoea was defined as a reduction by $50 \%$ of the flow signal for 10 $\mathrm{s}$ or more when compared to the peak amplitude obtained over a $10 \mathrm{~s}$ period within the last $2 \mathrm{~min}$ [13]. Thoracic movements were recorded using a strain gauge. Two thermistors were fixed in front of the nostrils and one in front of the mouth to detect the route of breathing. With rare exceptions, subjects breathed through the nose all night. The 200 breaths analysed for flow limitation were all through the nose. Transcutaneous oxygen saturation and pulse rate were monitored by a Nellcor pulse oximeter.

Data between groups were compared using the MannWhitney U-test, and a p-value $<0.05$ was considered significant.

\section{Results}

The four heavy snorers ( 2 females and 2 males) had a mean \pm SD age of $43 \pm 12$ yrs and a body mass index (BMI) of $30 \pm 9 \mathrm{~kg} \cdot \mathrm{m}^{-2}$. The five OSA patients (all males) were older $(51 \pm 6 \mathrm{yrs})(\mathrm{p}<0.05)$ and had a higher BMI of $35 \pm 5 \mathrm{~kg} \cdot \mathrm{m}^{-2}(\mathrm{p}>0.05)$.

Sleep characteristics of the two groups (without the pharyngeal catheter) are presented in table 1 . The short total sleep time (TST) in heavy snorers is due to the fact that it was recorded after the withdrawal of the pharyngeal catheter (i.e. following the measurements of upper airways mechanics). Table 2 presents the sleep characteristics of heavy snorers, with and without the pharyngeal catheter. With the catheter in place, rapid eye movement (REM) sleep was absent in all heavy snorers. After the withdrawal of the catheter, all sleep stages were present. In heavy snorers, $P_{\text {sg }}$ and $V^{\prime}$ were recorded during stages 1 and 2 non-REM (NREM) sleep. In OSA patients we assume that $P_{\mathrm{sg}}$ and $V^{\prime}$ were also

Table 2. - Sleep characteristics of heavy snorers (HS) with and without the pharyngeal catheter

\begin{tabular}{|c|c|c|c|}
\hline \multicolumn{2}{|c|}{ Sleep stage } & $\begin{array}{c}\text { HS with catheter } \\
\% \text { TST } \\
\text { (56 min) }\end{array}$ & $\begin{array}{l}\text { HS without } \\
\text { catheter } \\
\% \text { TST } \\
(182 \mathrm{~min})\end{array}$ \\
\hline REM & & 0 & 16 \\
\hline NREM & 1 & 17 & 9 \\
\hline & 2 & 66 & 49 \\
\hline & 3 & 6 & 8 \\
\hline & 4 & 11 & 20 \\
\hline
\end{tabular}

For definitions see legend to table 1 .

Table 1. - Sleep characteristics of heavy snorers (HS) and OSA patients without pharyngeal catheter

\begin{tabular}{|c|c|c|c|c|c|c|c|c|c|c|c|}
\hline & $\begin{array}{l}\text { TST } \\
\text { min }\end{array}$ & $\begin{array}{l}\text { REM } \\
\% \text { TST }\end{array}$ & $\begin{array}{l}\text { NREM } 1 \\
\% \text { TST }\end{array}$ & $\begin{array}{l}\text { NREM } 2 \\
\% \text { TST }\end{array}$ & $\begin{array}{c}\text { NREM } 3 \\
\% \text { TST }\end{array}$ & $\begin{array}{c}\text { NREM } 4 \\
\% \text { TST }\end{array}$ & $\underset{\text { events }}{\text { AI }} \mathrm{h}^{-1}$ & $\begin{array}{c}\mathrm{W} \\
\mathrm{Sa}_{\mathrm{a}, \mathrm{O}_{2}} \%\end{array}$ & $\begin{array}{c}\text { REM } \\
{\mathrm{Sa}, \mathrm{O}_{2}}_{2} \%\end{array}$ & $\begin{array}{l}\text { NREM } \\
\mathrm{S}_{\mathrm{a}, \mathrm{O}_{2}} \%\end{array}$ & $\begin{array}{c}\mathrm{HI} \\
\text { events } \cdot \mathrm{h}^{-1}\end{array}$ \\
\hline $\begin{array}{l}\mathrm{HS} \\
\mathrm{n}=4\end{array}$ & $182 \pm 54$ & $14 \pm 10$ & $11 \pm 7$ & $46 \pm 5$ & $9 \pm 6$ & $20 \pm 9$ & 0 & $97 \pm 0.5$ & $96.5 \pm 0.6$ & $96.5 \pm 1$ & $13.3 \pm 13.2$ \\
\hline $\begin{array}{l}\text { OSA } \\
n=5\end{array}$ & $416 \pm 46^{*}$ & $15 \pm 10$ & $42 \pm 28$ & $39 \pm 24$ & $2.5 \pm 3$ & $0.4 \pm 0.8 *$ & $33 \pm 17 *$ & $94 \pm 2 *$ & $89 \pm 5^{*}$ & $91 \pm 2 *$ & $38.0 \pm 37.0$ \\
\hline
\end{tabular}

Values are presented as mean \pm SD. OSA: obstructive sleep apnoea; TST: total sleep time; REM: rapid eye movement sleep; NREM 1, 2, 3 and 4: stages of non-rapid eye movement sleep; AI: apnoea index; HI: hypopnoea index; $\mathrm{Sa}_{2} \mathrm{O}_{2}$ : arterial oxygen saturation; W: during wakefulness. *: $\mathrm{p}<0.05$, compared to heavy snorers. 


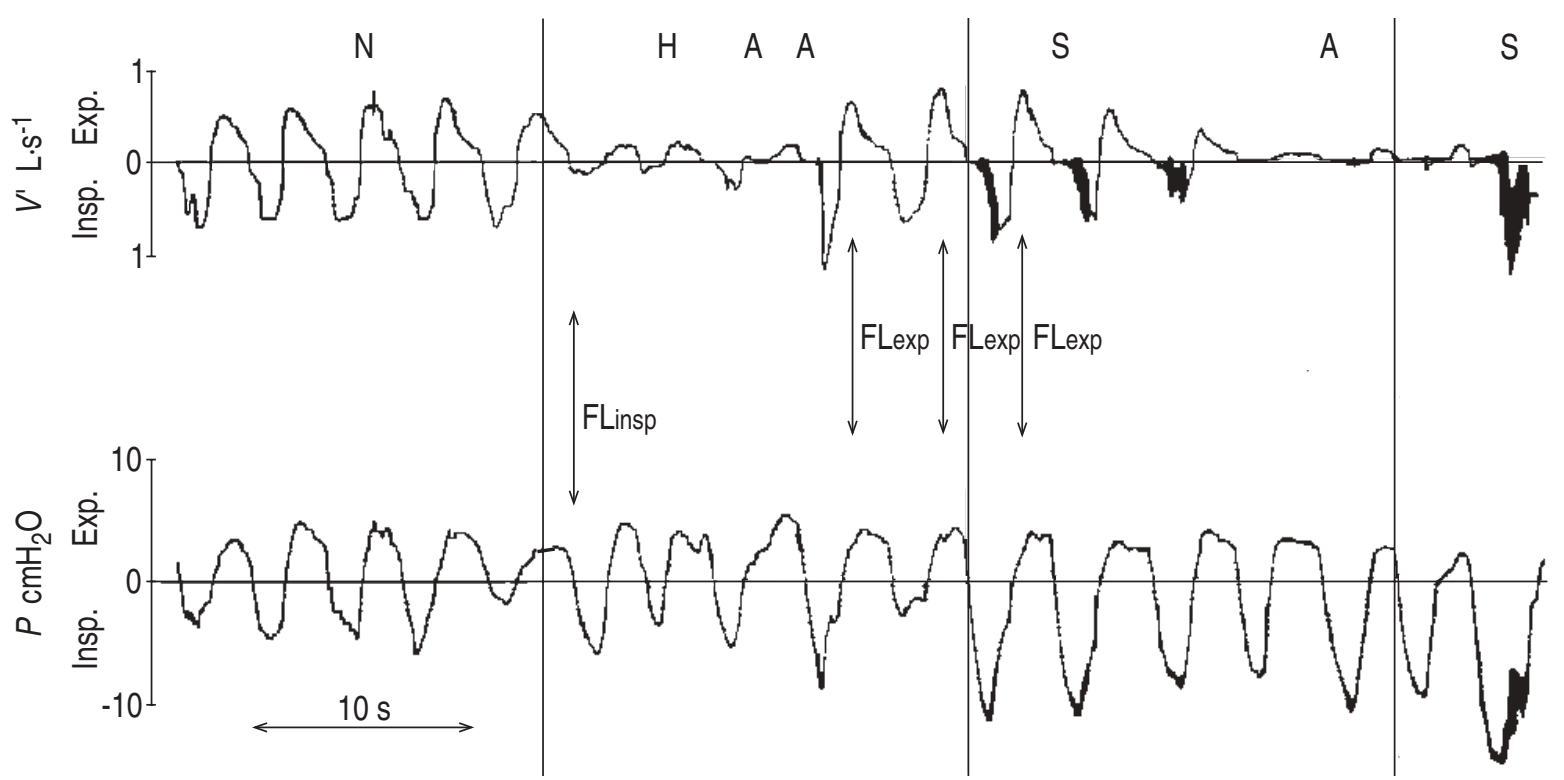

Fig. 1. - Supraglottic pressure $(P)$ and flow rate $\left(V^{\prime}\right)$ in an OSA patient during sleep. Periods of normal breathing $(\mathrm{N})$, hypopnoea $(\mathrm{H})$, apnoea (A), inspiratory (FLinsp) and expiratory (FLexp) flow limitation, and snoring (S) are evident. Exp.: expiration; Insp.: inspiration.

recorded in light NREM sleep. Indeed, during the polysomnographic night, with a less invasive procedure, patients showed only about $3 \%$ of deep NREM sleep. With a catheter in the pharynx, which alters the sleep, a more profound NREM sleep is not likely to have occurred.

Flow limitation occurred as an isolated, inspiratory or expiratory, event or as coupled breaths, inspiratory followed by expiratory flow limitation (figs. 1 and 2). The percentage of flow limited events in the 200 breaths is presented in table 3 . About $20 \%$ of the respiratory cycles presented isolated inspiratory flow limitation, and about the same percentage was observed in heavy snorers and OSA patients. Isolated expiratory flow limitations were less frequently recorded. Coupled inspiratory and expiratory flow limitations were more numerous, especially in heavy snorers. Examples of isolated inspiratory, isolated expiratory and coupled inspiratory and expiratory flow limitations are shown if figures 3, 4 and 5. Mean values of flow limited breaths were not statistically different $(p>0.05)$ between heavy snorers and OSA patients. Mean value for linear supraglottic resistance was

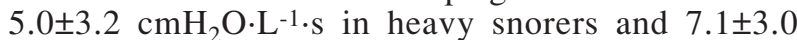
$\mathrm{cmH}_{2} \mathrm{O} \cdot \mathrm{L}^{-1} \cdot \mathrm{s}$ in OSA patients $(\mathrm{p}>0.05)$. Hysteresis was recorded both in snorers and OSA patients. There was either inspiratory hysteresis (fig. 6), expiratory hysteresis or both.

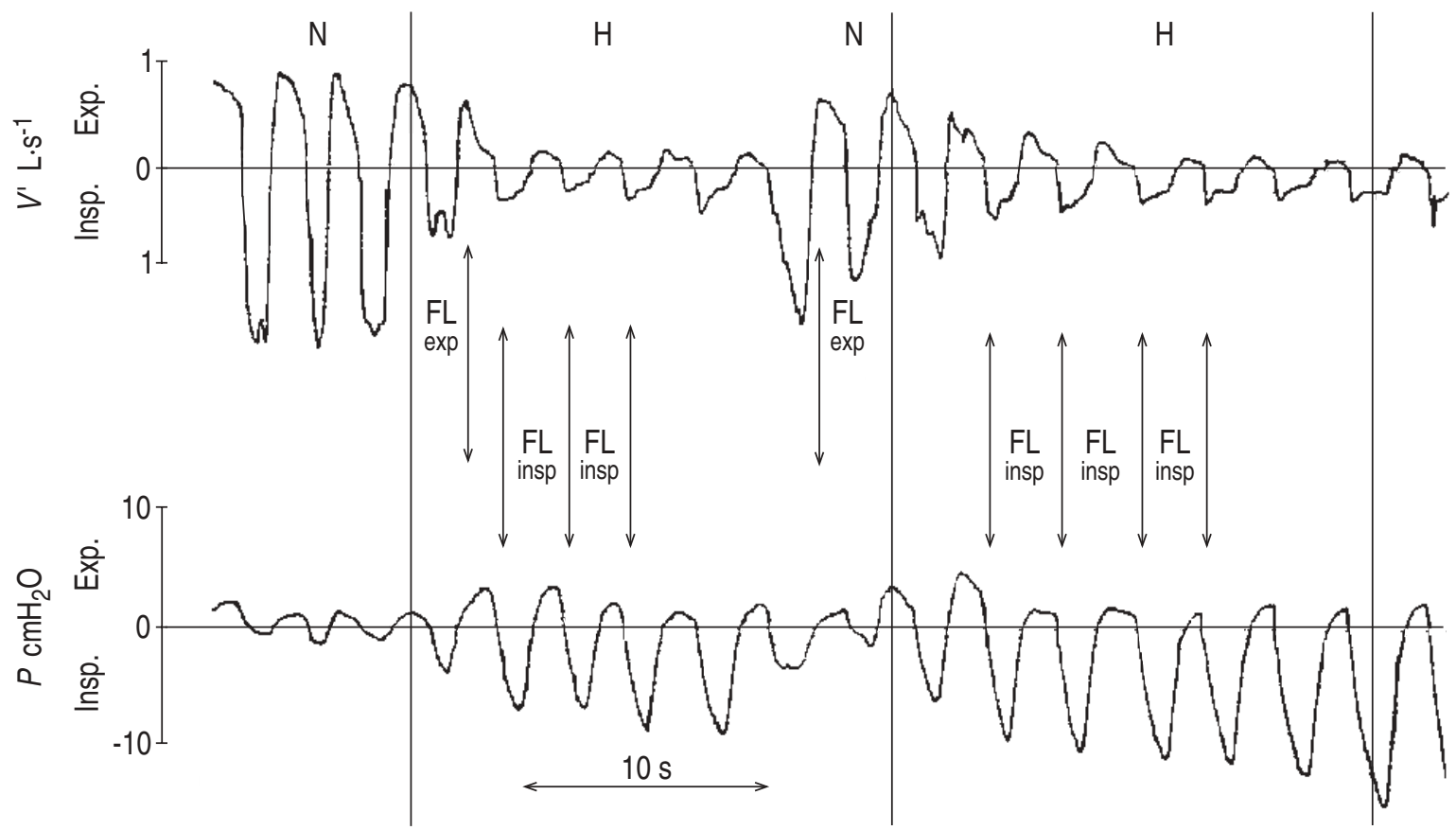

Fig. 2. - Supraglottic pressure $(P)$ and flow rate $\left(V^{\prime}\right)$ in another OSA patient during sleep. One can see a period of normal breathing (N), hypopnoea $(\mathrm{H})$, inspiratory (FLinsp) and expiratory (FLexp) flow limitation. Exp.: expiration; Insp.: inspiration. 
Table 3. - The percentage of flow limited events

\begin{tabular}{lccc}
\hline & $\begin{array}{c}\text { Isolated FLinsp } \\
\%\end{array}$ & $\begin{array}{c}\text { Isolated FLexp } \\
\%\end{array}$ & $\begin{array}{c}\text { Coupled FLinsp } \\
\text { and FLexp } \%\end{array}$ \\
\hline Heavy snorers & $\mathbf{n}$ & & \\
1 & 1 & 7 & 92 \\
2 & 38 & 14 & 3 \\
3 & 11 & 11 & 67 \\
4 & 28 & 5 & 53 \\
Mean \pm SD & $20 \pm 17$ & $9 \pm 4$ & $54 \pm 38$ \\
OSA patients & $\mathbf{n}$ & & \\
1 & 13 & 17 & 22 \\
2 & 13 & 10 & 60 \\
3 & 19 & 19 & 10 \\
4 & 26 & 0 & 0 \\
5 & 9 & 0 & 0 \\
Mean \pm SD & $16 \pm 7$ & $9 \pm 9$ & $18 \pm 25$ \\
\hline
\end{tabular}

n: number of subject; FLinsp: inspiratory flow limitation; FLexp: expiratory flow limitation; HS: heavy snorers; OSA: obstructive sleep apnoea.

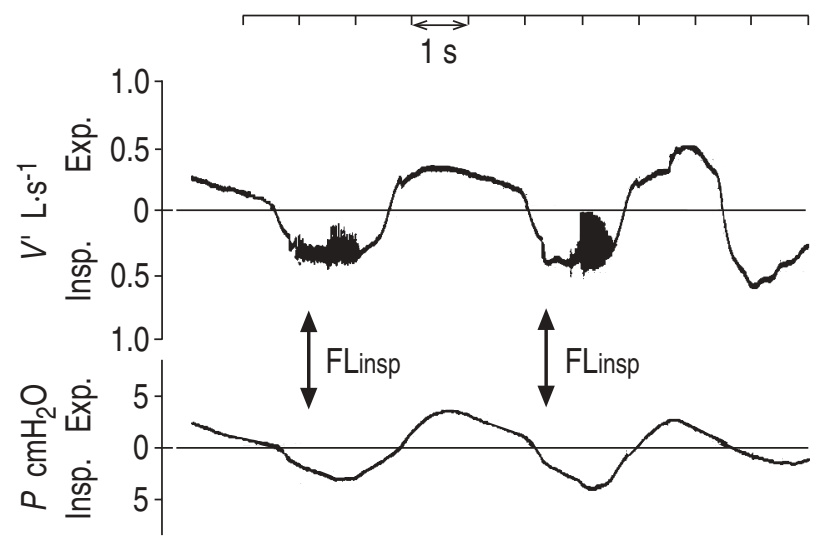

Fig. 3. - Isolated inspiratory flow limitation (FLinsp) in a heavy snorer. Note an increase in supraglottic pressure $(P)$ (more negative) and a plateau of inspiratory flow $\left(V^{\prime}\right)$. Note also high frequency flow oscillations, corresponding to snoring. Exp.: expiration; Insp.: inspiration.

$1 \mathrm{~s}$
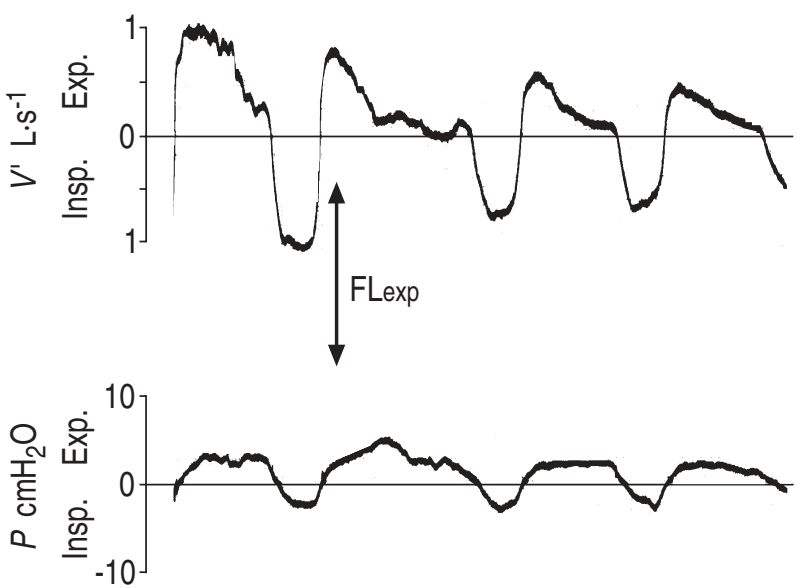

Fig. 4. - Isolated expiratory flow limitation (FLexp) in an OSA patient. Note an increase in supraglottic pressure $(P)$ (more positive) simultaneously with a decrease in flow rate $\left(V^{\prime}\right)$. Insp.: inspiration; Exp.: expiration.

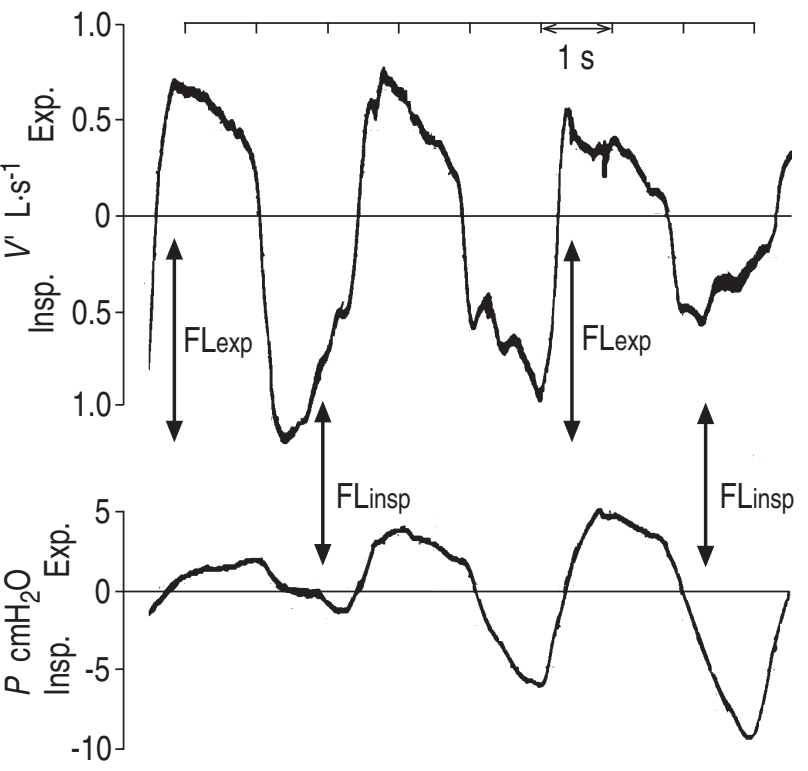

Fig. 5. - Coupled inspiratory (FLinsp) and expiratory (FLexp) flow limitation in a heavy snorer. $V^{\prime}$ : flow rate; $P$ : pressure; Exp.: expiration; Insp.: inspiration.

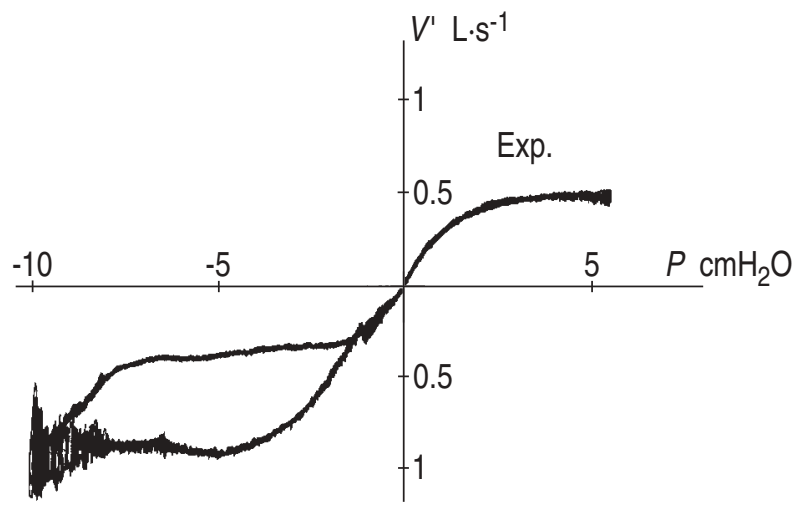

Insp.

Fig. 6. - An example of inspiratory (Insp.) and expiratory (Exp.) flow limitation in an OSA patient. Signals of flow $\left(V^{\prime}\right)$ and pressure $(P)$ recorded on tape were displayed on a storage oscilloscope and photographed (redrawn from the original). Note pressure and flow oscillations (corresponding to snoring), and hysteresis during inspiration. Other signals (thoracic movements and signals from thermistors) were omitted from this and the previous figures. OSA: obstructive sleep apnoea.

\section{Discussion}

We have observed the occurrence of expiratory flow limitation during sleep in 3 out of 5 OSA patients and in all heavy snorers studied. Expiratory flow limitations occurred as isolated events (figs. 3 and 4), or coupled i.e. inspiratory followed by expiratory flow limitation (fig. 5). Inspiratory flow limitation was recorded in all subjects studied. To our knowledge, this is the first time that expiratory flow limitation during sleep has been reported.

There are several limitations to this study. In heavy snorers, measurement of upper airways mechanics were made simultaneously with the polysomnographic recordings on the same night. In OSA patients sleep was assessed by behavioural criteria. In as much as behavioural criteria for defining sleep are less accurate than 
electroencephalographic (EEG) criteria, breaths which were not flow limited could have occurred during a brief arousal. This might have resulted in an underestimation of the actual number of flow limited breaths. The sample studied was small, and the lack of statistical differences between the two groups of subjects has to be accepted with caution. However, the small size cannot deny the main finding of this study, namely the presence of expiratory flow limitation occurring during sleep in all snorers and most of the OSA patients. Measurements of upper airway mechanics were performed more than $30 \mathrm{~min}$ after local anaesthesia. We have previously shown [14] that most of the effect of lidocaine on upper airway muscles (at a much larger dose than in the present study) had disappeared by that time. The localization of the upper airway flow limiting segment was not determined in this study. However, it must be located above the tip of the catheter, i.e. above the glottis.

Inspiratory, but not expiratory, flow limitation was previously reported during sleep in patients with OSA, in healthy snorers $[2,3]$ and in healthy nonobese nonsnorers [1]. Models using collapsible tubes have shown that, once a critical narrowing is reached, flow does not increase any further, and might even decrease, despite an increase in intraluminal pressure. Flow limitation is associated with high frequency oscillations of the wall of the tube, which are propagated to the mass of fluid $[15,16]$. According to current concepts, during wakefulness inspiratory activation of dilator muscles keeps the upper airway open; thus, balancing the negative intraluminal pressure generated by the chest wall inspiratory muscles. During sleep, the decrease in muscle tone results in inspiratory narrowing and, eventually, closure of the pharyngeal airway $[17,18]$. In terms of flow rate, this corresponds to flow limitation, high frequency flow oscillations (snoring) and eventually apnoea.

During expiration, since intraluminal, and therefore transmural, pressure is positive, narrowing and closure of the upper airway is not supposed to occur. This view is contradicted by the present findings that flow limitation also occurs during expiration. Two mechanisms can explain sleep-related flow limitation during expiration. An active contraction of pharyngeal constrictor muscles or, paradoxically, a decrease in their tone. Both mechanisms would result in expiratory narrowing of the upper airway. The latter mechanism, which we favour, is based on the assumption that not only inspiratory (dilator) but also expiratory (constrictor) muscles are activated during wakefulness, and that sleep induces a decrease and, eventually, lack of tone of both these muscles, thus destabilizing the upper airway.

Hill et al. [19] and SAUERLAND et al. [20] found electromyographic (EMG) discharges of the superior and middle pharyngeal constrictors during sleep in normal subjects and OSA patients. We recently observed inspiratory and expiratory flow limitation in awake healthy subjects and OSA patients during muscular relaxation. Fibreoptic bronchoscopy showed a wide open oropharyngeal isthmus during active breathing. During relaxation, the soft palate fell and the base of the tongue rose, resulting in a narrowed orifice. This was true both during inspiration and expiration [6,11]. These findings demonstrate that active breathing maintains a wide open pharyngeal airway; and that muscular relaxation results in a critical narrowing of this airway and flow limitation during both inspiration and expiration. We suggest that the same mechanism was operating in the subjects investigated in this study during sleep. Indeed, the decrease in tone of the respiratory muscles during relaxation may be related to the decrease in tone of these muscles during sleep.

Several previous reports are in keeping with the present observations. In a paper by LUGARESI et al. [21] there is a clear illustration of expiratory flow limitation in a heavy snorer (but without any comment). Recently, KAYALEH et al. [7] have reported changes in the shape of the tidal breath expiratory flow-volume curve during relaxation in supine subjects, reflecting expiratory upper airways obstruction. Previously, SANDERS and MOORE [8] have suggested that upper airways are substantially narrowed during expiration in OSA. Recently, SchwAB et al. [22], using cine-computed tomography in supine, awake, normal subjects and OSA patients, found that at end-expiration the upper airway narrowed significantly. SANDERS and KERN [9] have shown that in OSA patients a critical level of expiratory positive airway pressure (EPAP) is "essential for uninterrupted upper airway patency during sleep". This is in keeping with the findings of MAHADEVIA et al. [10], who reported that $10 \mathrm{cmH}_{2} \mathrm{O}$ of EPAP significantly reduces frequency and duration of apnoeas and the degree of nocturnal oxygen desaturation.

In conclusion, we have recorded expiratory and inspiratory flow limitation during sleep both in heavy snorers and obstructive sleep apnoea patients. Present, as well as previous results, suggest that upper airway obstruction during sleep is both an inspiratory and expiratory event.

Acknowledgements: The authors thank D. Rodenstein for helpful suggestions.

\section{References}

1. Hudgel DW, Curtis H, Hamilton HB. Characteristics of the upper airway pressure-flow relationship during sleep. J Appl Physiol 1988; 64: 1930-1935.

2. Skatrud JB, Dempsey JA. Airway resistance and respiratory muscle function in snorers during NREM sleep. J Appl Physiol 1985; 59: 328-335.

3. Liistro G, Stănescu DC, Veriter C, Rodenstein DO, Aubert-Tulkens G. Pattern of snoring in obstructive sleep apnea patients and in heavy snorers. Sleep 1991; 14: 517-525.

4. Remmers JE, Feroah T, Perez-Padilla JR, Whitelaw WA. Correlation of structure and mechanics in pharyngeal obstruction during sleep. In: Chourd $\mathrm{CH}$, ed. Chronic Rhonchopathy. Paris, Libbey, 1987; pp. 30-35.

5. Sanna A, Veriter C, Kurtansky A, Stănescu D. Contraction and relaxation of upper airway muscles during expiratory application of negative pressure at the mouth. Sleep 1994; 17: 220-225.

6. Sanna A, Veriter C, Stănescu D. Expiratory supraglottic obstruction during muscular relaxation. Chest 1995; 108: 143-149.

7. Kayaleh RA, Dutt A, Khan A, Wilson AF. Tidal breath flow-volume curves in obstructive sleep apnea. Am Rev Respir Dis 1992; 145: 1372-1377. 
8. Sanders MH, Moore SE. Inspiratory and expiratory partitioning of airway resistance during sleep in patients with sleep apnea. Am Rev Respir Dis 1983; 127: 554-558.

9. Sanders MH, Kern N. Obstructive sleep apnea treated by independently adjusted inspiratory and expiratory positive airway pressures via nasal mask. Chest 1990; 98: 317-324.

10. Mahadevia AK, Önal E, Lopata M. Effects of expiratory positive airway pressure on sleep-induced respiratory abnormalities in patients with hypersomnia-sleep apnea syndrome. Am Rev Respir Dis 1983; 128: 708-711.

11. Sanna A, Veriter C, Stănescu D. Upper airway obstruction induced by negative-pressure ventilation in awake healthy subjects. J Appl Physiol 1993; 75: 546-552.

12. Rechtschaffen A, Kales A. A manual of standardized terminology, techniques and scoring system for sleep stages of human subjects. Washington, DC, US Government Printing Office, 1968; NIH Publication No. 204.

13. Gould GA, Whyte KF, Rhind GB, et al. The sleep hypopnoea syndrome. Am Rev Respir Dis 1988; 137: 895-898.

14. Liistro G, Stănescu DC, Veriter C, Rodenstein DO, D'Odemont JP. Upper airway anesthesia induces airflow limitation in awake humans. Am Rev Respir Dis 1992 146: 581-585.

15. Conrad WA. Pressure-flow relationships in collapsible tubes. IEEE Trans Biomed Eng 1969; 16: 284-295.

16. Gravriely N, Shee TR, Cugell DW, Grotbert JB. Flutter in flow-limited collapsible tubes: a mechanism for generation of wheezes. J Appl Physiol 1989; 66: 22512261.

17. Hudgel DW. Variable size of airway narrowing among obstructive sleep apnea patients. J Appl Physiol 1986; 61: 1403-1409.

18. Hudgel DW, Hendricks C. Palate and hypopharynx: sites of inspiratory narrowing of the upper airway during sleep. Am Rev Respir Dis 1988; 138: 1542-1547.

19. Hill MV, Guilleminault C, Simmons FB. Fiberoptic and EMG studies in hypersomnia sleep-related apnea syndrome. In: Guilleminault C, Dement WC, eds. Sleep Apnea Syndromes. New York, Alan R. Liss Inc, 1978; pp. 249-258.

20. Sauerland EK, Orr WC, Hairston LE. EMG patterns of oropharyngeal muscles during respiration in wakefulness and sleep. Electromyogr Clin Neurophysiol 1981; 21: 307-316.

21. Lugaresi E, Goccagna G, Cirignotta F. Snoring and its clinical implications. In: Guilleminault C, Dement WC, eds. Sleep Apnea Syndromes. New York, Alan R. Liss Inc, 1978; pp. 13-21.

22. Schwab RJ, Gefter WB, Hoffman EA, Gupta KB, Pack AI. Dynamic upper airway imaging during awake respiration in normal subjects and patients with sleepdisordered breathing. Am Rev Respir Dis 1993; 148: 1385-1400. 